\title{
Bleeding tendency in dual antiplatelet therapy with aspirin/clopidogrel: rescue of the template bleeding time in a single-center prospective study
}

Raul Altman ${ }^{1 *}$, Ana J Rivas ${ }^{1}$ and Claudio D Gonzalez ${ }^{2,3}$

\begin{abstract}
Background: Patients with heightened platelet reactivity in response to antiplatelet agents are at an increased risk of recurrent ischemic events. However, there is a lack of diagnostic criteria for increased response to combined aspirin/clopidogrel therapy. The challenge is to identify patients at risk of bleeding. This study sought to characterize bleeding tendency in patients treated with aspirin and clopidogrel.

Patients/methods: In a single-center prospective study, 100 patients under long-term aspirin/clopidogrel treatment, the effect of therapy was assayed by template bleeding time (BT) and the inhibition of platelet aggregation (IPA) by light transmission aggregometry (LTA). Arachidonic acid $(0.625 \mathrm{mmol} / \mathrm{L})$ and adenosine diphosphate (ADP; 2,4 , and $8 \mu \mathrm{mol} / \mathrm{L}$ ) were used as platelet agonists.
\end{abstract}

Results: Bleeding episodes (28 nuisance, 2 hematuria [1 severe], 1 severe proctorrhagia, 1 severe epistaxis) were significantly more frequent in patients with longer BT. Template BT $\geq 24$ min was associated with bleeding episodes (28 of 32). Risk of bleeding increased 17.4\% for each 1 min increase in BT. Correlation was found between BT and IPAmax in response to ADP $2 \mu \mathrm{mol} / \mathrm{L}$ but not to ADP 4 or $8 \mu \mathrm{mol} / \mathrm{L}$.

Conclusion: In patients treated with dual aspirin/clopidogrel therapy, nuisance and internal bleeding were significantly associated with template BT and with IPAmax in response to ADP $2 \mu \mathrm{mol} / \mathrm{L}$ but not in response to ADP $4 \mu \mathrm{mol} / \mathrm{L}$ or $8 \mu \mathrm{mol} / \mathrm{L}$.

Keywords: nuisance bleeding, bleeding time, platelet, inhibition of platelet aggregation, IPA

\section{Introduction}

Until recently, long-term antiplatelet therapy for the prevention of atherothrombotic disease was limited to aspirin (ASA). The availability of thienopyridines, particularly clopidogrel (CLOP), represented an important addition to the physician's armamentarium. The combination of CLOP and ASA in patients with acute coronary syndrome (ACS) reduces the risk of reinfarction, stroke, and death by $20 \%$ compared with ASA alone [1]. Nevertheless, the current therapy options for these patients are suboptimal. Despite the use of available antiplatelet therapies, the recurrence of ischemic events in patients

\footnotetext{
*Correspondence: draltman@arnet.com.ar

${ }^{1}$ Centro de Trombosis de Buenos Aires, Buenos Aires, Argentina

Full list of author information is available at the end of the article
}

with ACS is still increasing and bleeding remains an important, and often underappreciated, risk with these therapies. Patient noncompliance because of bleeding contributes to thrombosis events.

The exact mechanism of benefit has not yet been elucidated but is clearly related not just to inhibition of platelet aggregation (IPA) but also to modification of the many consequences of the platelet activation-endothelial relationships [2]. The current gold standard for testing platelet function is light transmission platelet aggregometry (LTA), which is used to categorize patients receiving ASA and/or CLOP therapy as responders or nonresponders.

Several published studies deal with low platelet responsiveness, the diagnosis of platelet resistance or platelet failure [3] and show that patients with heightened platelet

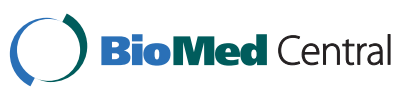

(c) 2012 Altman et al; licensee BioMed Central Ltd. This is an Open Access article distributed under the terms of the Creative Commons Attribution License (http://creativecommons.org/licenses/by/2.0), which permits unrestricted use, distribution, and reproduction in any medium, provided the original work is properly cited. 
reactivity to antiplatelet agents (ie, low IPA) might be at increased risk of recurrent ischemic events, particularly when they undergo percutaneous coronary intervention [4-6].

But the clear challenge of responsiveness to ASA, CLOP, and other thienopyridine derivatives is to identify the patients at risk of bleeding who will benefit from antiplatelet therapy without hemorrhagic complications. Effectiveness (thrombosis prevention) with adequate safety (no or few hemorrhagic events) is an unresolved clinical problem, and the issue remains constrained by considerable differences between testing methods. A potential association between platelet response and bleeding in patients on combined therapy of aspirin and clopidogrel undergoing coronary stent placement [7] and in other clinical situations [8] has been reported.

This prospective observational study was designed to determine the relationship between template bleeding time (BT) and bleeding complications in patients receiving ASA and CLOP. We also sought to determine if there is a correlation between BT and IPA through LTA studies of platelet-rich plasma (PRP).

\section{Methods}

\section{Patients}

We enrolled 109 patients (67 men, 42 women) who were referred to our Thrombosis Center for thrombophilia screening. Nine patients were excluded at entry (5 men, 4 women): 3 because of a history of superficial or nuisance bleeding, 1 because of von Willebrand disease, 1 because of essential thrombocytemia, 1 with ischemic optical neuritis, 1 with Raynaud syndrome, and 2 with amaurosis fugax, Thus, 100 patients treated with dual antiplatelet therapy, indicated by their own physician (81-100 mg ASA daily and $75 \mathrm{mg}$ CLOP daily), were included in the study. This study was approved by the review board and all participants provided informed consent before being enrolled in the study.

The study participants included 62 men and 38 women, mean age 61.4 $(\mathrm{SD} \pm 11.8)$ years, median age 62 years, range 35-83 years) with no history of hemorrhagic diseases referred because of previous vascular cerebral symptomatology (1 stroke, 19 transient ischemic events, 17 with ischemic cerebral focus by nuclear magnetic resonance), myocardial infarction or coronary artery bypass graft $(n=$ $14)$, one or multiple coronary stents $(n=46,38$ coronary drug-eluting stents), and peripheral arterial disease $(n=3)$. Bleeding was defined according to Ben-Dor et al. [9]: alarming bleeding, internal bleeding, and nuisance bleeding. Internal bleeding included hematoma, epistaxis, vaginal bleeding, melena, hematemesis, eye bleeding, and haematuria. Nuisance bleeding included easy bruising, bleeding from small cuts, petechia, and ecchymosis and was assessed during routine clinical follow-up. Only one bleeding episode was recorded for each patient.

\section{Additional Medical Therapy}

Most patients were receiving additional therapy at the time of the study: antidepressants $(n=6)$, antidiabetics $(n=11)$, anxiolytics $(n=26)$, beta-blockers $(n=36)$, ACE inhibitors $(n=23)$, folic acid $(n=11)$, lipid-lowering agents $(n=53)$, protein pump inhibitor (PPI) $(n=$ 16,7 on omeprazol), levothyroxine $(n=7)$, and diuretics $(n=3)$. Drug-drug interaction between the PPI omeprazole and CLOP that attenuates the antiplatelet effect has been described recently but is not yet widely accepted [10-13]; the US Food and Drug Administration has alerted the public to new safety information concerning an interaction between the 2 therapies. Because of these contradicting publications and, to the best of our knowledge, the absence of any publications showing that PPI drugs affect BT, patients receiving omeprazole therapy were not excluded from the study. None of the patients were receiving anticoagulant therapy.

Patients presented several comorbidities including diabetes (11\%), hypertension (57\%), and dyslipidemia (53\%); $5 \%$ had peripheral vascular disease. No patients were active smokers. The mean number of weeks on clopidogrel + aspirin was $28.3 \pm 10.6$ weeks $(\max 58$ weeks, min 12 weeks).

\section{Hemostasis Tests and Bleeding Time}

Venous blood was drawn from the antecubital vein without stasis and mixed with $0.11 \mathrm{~mol} / \mathrm{L}$ sodium citrate $(1: 10 \mathrm{v} / \mathrm{v})$. PRP was obtained by centrifugation at $150 \times g$ for $10 \mathrm{~min}$ at room temperature; platelet-poor plasma (PPP) was obtained by centrifugation of PRP at $900 \times g$ for $15 \mathrm{~min}$ at $20^{\circ} \mathrm{C}$. The PRP was adjusted to a platelet count of $290,000-310,000 / \mu \mathrm{L}$ with autologous PPP. If contamination of the PRP with erythrocytes or leukocytes was observed by light microscopy, a second centrifugation at $900 \times g$ for $5 \mathrm{~min}$ was carried out to minimize the cell number. Plastic syringes, tubes, and pipettes were used for all tests. LTA of the PRP was performed in a double-channel Lumi-Aggregometer (Chrono-log Corp., Havertown, PA, USA). Light transmission was set at $10 \%$ for PRP and 90\% for PPP. The aggregating agent (1-10 $\mu \mathrm{L}$ ) was added to PRP in the aggregometer at $37^{\circ} \mathrm{C}$ with constant stirring $(1000 \mathrm{rpm})$. Arachidonic acid (AA) sodium salt (0.625 mmol/L; Sigma, St. Louis, MO, USA) and adenosine diphosphate (ADP; 2,4 , and $8 \mu \mathrm{mol} / \mathrm{L}$; Sigma, St. Louis, MO, USA) were used as platelet agonists in the aggregation studies. The percentage IPA was expressed as $100 \%$ minus the maximal percent change in light transmission from baseline with PPP used as a reference. 
For BT, a disposable Surgicutt adult device (ITC, Thoratec Co, Edison, NJ, USA) was used to make a standard incision (5-mm long, 1-mm deep) on the volar surface of the forearm, perpendicular to the antecubital crease, while maintaining a pressure of $40 \mathrm{mmHg}$ in a sphygmomanometer cuff. The time until complete cessation of bleeding (to the nearest $30 \mathrm{~s}$ ) was recorded as the BT. Bleeding was followed for a maximum of $26 \mathrm{~min}$. The BT and analysis of platelet function were performed in the morning of the same day.

Basic hemostasis studies, prothrombin time, activated partial prothrombin time, and platelet count were performed at entry. Other tests exploring hemostasis were performed when indicated. Platelet function analyses were performed in accordance with a standardized protocol by the same trained technician, who was not aware of the study objectives or drug intake.

\section{Statistical Analysis}

The nature of the quantitative variable distribution was evaluated by the Shapiro-Wilk test. Differences among groups of quantitative data were explored by ANOVA (Bonferroni post hoc test) or Kruskal-Wallis test in correspondence with the distribution of the variables. Differences among groups in terms of the frequency of patients reporting nuisance bleeding were evaluated by the chisquare test. Correlation between BT and IPA was explored using the Spearman rank order method. The association between nuisance bleeding and quantitative variables, such as BT and IPA, was studied using receiver operating curves (ROC) by obtaining the corresponding area under the curve (AUC) values and their standard errors. Cutoff points were also obtained. The multivariate association between bleeding and BT, (adjusted for gender, age, and IPA) was explored by multiple logistic regression (maximum likelihood; quasi-Newton). Significance was set at $P<0.05$.

\section{Results}

In our population, the mean BT was $21.5 \pm 6.2 \mathrm{~min}$, ranging from $4 \mathrm{~min}$ to more than $26 \mathrm{~min}$. The incidence of bleeding was $32 \%$. Fifty-two patients had a BT longer than 26 min: 21 nuisance bleeding, 2 internal bleeding (1 severe hematuria, 1 epistaxis), and 1 alarming bleeding (proctorrhagia with life compromise requiring transfusion). Seventeen patients had a BT longer than 20.5 min and less than 26 min: 5 nuisance bleeding and 1 internal bleeding (mild hematuria) which stopped after discontinuation of platelet inhibitory agents.

The PRP was activated with $0.625 \mathrm{mmol} / \mathrm{L} \mathrm{AA}$ or 2,4 , or $8 \mu \mathrm{mol} / \mathrm{L}$ ADP. The maximal aggregation at each agonist concentration was taken as the IPA for the calculations.
The IPA resulting from the maximal AA-induced LTA was not different among patients with or without bleeding episodes (Table 1). As expected, there was an inverse correlation between ADP concentration and IPAmax. The Spearman rank order method showed a weak significant correlation between BT and IPAmax (correlation between BT and ADP $2 \mu \mathrm{mol} / \mathrm{L}, r=0.32$, $P=0.001$; between BT and ADP $4 \mu \mathrm{mol} / \mathrm{L}, r=0.31$, $P=0.002$; between BT and ADP $8 \mu \mathrm{mol} / \mathrm{L}, r=0.38$, $P=0.0002)$.

In the univariate analysis (Table 2), bleeding events correlated significantly with BT (17\% of risk increase per minute of BT, $P=0.004$ ) and with ADP $2 \mu \mathrm{mol} / \mathrm{L}$ ( $4 \%$ of risk increase per $\mu \mathrm{mol} / \mathrm{L}, P=0.049)$. No correlation was found between bleeding and IPAmax in response to ADP $4 \mu \mathrm{mol} / \mathrm{L}$ or $8 \mu \mathrm{mol} / \mathrm{L}$. ROC analysis (Table 3) also demonstrated that bleeding events correlated significantly with BT and with IPAmax in response to ADP 2 $\mu \mathrm{mol} / \mathrm{L}$ but not in response to ADP $4 \mu \mathrm{mol} / \mathrm{L}$ or $8 \mu \mathrm{mol} /$ L. According to the ROC, 24 min appears to be the cutoff above which bleeding events are more frequent. In the multivariate logistic analysis, risk for nuisance bleeding was significantly associated with BT (after adjustment for age, gender and ADP2 max values). The multivariate OR was 1.16 per $\min$ (95\%CI: 1.04-1.30).

\section{Discussion}

Besides hyporesponsiveness to CLOP and other thienopyridine derivatives, the clear challenge of antithrombotic therapy is to identify the patients at risk of bleeding who will benefit from antiplatelet therapy without hemorrhagic complications. New data from a study by Shehab et al. [8] showed a substantial risk of bleeding with dual therapy of aspirin plus clopidogrel in a real-world setting.

This study was carried out on patients with vascular pathology or a coronary stent device under prolonged antiplatelets drugs to test the dual therapy effect through LTA and template bleeding time. Ideally, comparing variables measured before and after treatment allows the effect of therapy in each patient to be determined, but

Table 1 Mean value ( \pm SD) of BT and IPAmax in the study population in response to $A A$ and to different concentrations of ADP

\begin{tabular}{ll}
\hline Variable & \\
\hline Follow-up, weeks, (mean \pm SD) & $28.3 \pm 10.6$ \\
Bleeding time, min (mean \pm SD) & $21.5 \pm 6.2$ \\
AA $0.625 \mathrm{mmol} / \mathrm{L}$ IPAmax \%(mean \pm SD) & $96.2 \pm 4.5$ \\
ADP $2 \mu \mathrm{mol} / \mathrm{L}$ IPAmax \% (mean $\pm \mathrm{SD})$ & $75.6 \pm 13.5$ \\
ADP $4 \mu \mathrm{mol} / \mathrm{L}$ IPAmax \% (mean $\pm \mathrm{SD})$ & $69.4 \pm 13.4$ \\
ADP $8 \mu \mathrm{mol} / \mathrm{L}$ IPAmax \% (mean $\pm \mathrm{SD})$ & $65.0 \pm 13.3$ \\
Incidence of bleeding $\%$ ) & 32 \\
\hline
\end{tabular}


Table 2 Univariate associations between BT, IPAmax values in response to ADP (independent covariates) and nuisance bleeding (end point): logistic regression

\begin{tabular}{llll}
\hline Variables & Odds ratio & $\mathbf{9 5 \%} \mathbf{C l}$ & $\boldsymbol{P}$ value \\
\hline BT (per min) & 1.17 & $1.05-1.31$ & 0.0035 \\
ADP $2 \mu \mathrm{mol} / \mathrm{L}$ IPAmax \% & 1.04 & $1.00-1.08$ & 0.0488 \\
ADP $4 \mu \mathrm{mol} / \mathrm{L}$ IPAmax \% & 1.03 & $0.99-1.07$ & 0.0876 \\
ADP $8 \mu \mathrm{mol} / \mathrm{L}$ IPAmax \% & 1.02 & $0.98-1.06$ & 0.2102 \\
\hline
\end{tabular}

comparing BT or LTA at baseline and after treatment with antithrombotic drugs is difficult because patients usually receive treatment very early, before it is possible to perform hemostasis tests. There is no agreement on how responsiveness should be measured concerning devices and cutoff values [14-19].

In the current study, among the 100 patients included in the follow-up, 28 patients had nuisance bleeding, 2 patients had haematuria 1 had proctorrhagia, and 1 patient had epistaxis. Twenty-five patients with nuisance bleeding and the patients with haematuria, epistaxis, and proctorrhagia had longer BT. Twenty-eight of the 32 patients with bleeding episodes had a template BT $\geq 24$ min. The univariate analysis and ROC AUC showed that the bleeding events correlated with BT and with ADP 2 $\mu \mathrm{mol} / \mathrm{L}$. In the multiple logistic regression model (risk for nuisance bleeding of BT adjusted by ADP $2 \mu \mathrm{mol} / \mathrm{L}$, IPAmax (\% values)) significant correlation between BT and bleeding events was found (odds ratio (OR) per minute, 1.16 (95\% confidence interval (CI) 1.04-1.30, $P=$ $0.007)$. Moreover $\geq 24 \mathrm{~min}$ appears to be the cutoff above which nuisance bleeding or severe bleeding is more frequent.

The BTs were compared with regard to platelet aggregation. The IPA is derived from the maximal aggregation obtained in the LTA of PRP. The IPAmax in AA-activated PRP and ADP 4 and $8 \mu \mathrm{mol} / \mathrm{L}$ did not discriminate patients with bleeding tendency. The IPAmax in response to ADP $2 \mu \mathrm{mol} / \mathrm{L}$ does seem to be sensitive for predicting bleeding episodes in patients receiving ASA plus CLOP treatment.

The BT, as well as LTA, is considered to be an inaccurate and poorly reproducible technique, which is dependent on several variables. Therefore, these methods could be inappropriate for measuring platelet inhibition activity

Table 3 Association between BT, IPAmax values and nuisance bleeding: ROC AUC

\begin{tabular}{llll}
\hline Quantitative variable & ROC AUC & 95\%Cl for AUC & $P$ value \\
\hline BT (min) & 0.695 & $0.595-0.783$ & 0.0009 \\
ADP $2 \mu \mathrm{mol} / \mathrm{L} \mathrm{IPA} \mathrm{max} \mathrm{( \% )}$ & 0.631 & $0.529-0.725$ & 0.0330 \\
ADP $4 \mu \mathrm{mol} / \mathrm{L} \mathrm{IPA} \max (\%)$ & 0.597 & $0.495-0.694$ & 0.1170 \\
ADP $8 \mu \mathrm{mol} / \mathrm{L} \mathrm{IPA} \max (\%)$ & 0.565 & $0.462-0.663$ & 0.3016
\end{tabular}

$[20,21]$. Nevertheless, LTA is the gold standard test of platelet function and is used to categorize patients receiving ASA, CLOP, or dual therapy as responders or nonresponders or to define drug resistance. In addition, a recent paper used LTA to compare IPA between patients receiving ticagrelor or CLOP therapy [22]. Antonino et al. [23] found a strong correlation $(P \leq 0.04)$ between LTA and flow cytometric measurements. Gremmel et al. [24] found that the results from 4 different assays of platelet function significantly correlated with LTA, and Paniccia et al. [25] found a significant correlation between LTA and VerifyNow but not the PFA-100 assay. Recently, Bonello et al. [26] provided a consensus opinion on the definition of high on-treatment platelet reactivity to ADP based on various methods reported in the literature and proposed LTA as 1 of the 4 tests associated with clinical risk. Very recently, Parodi et al. [5] found that high residual platelet reactivity assessed by LTA and ADP as agonist among patients receiving clopidogrel after percutaneous coronary intervention (PCI) has been associated with a high risk of ischemic events at shortand long-term follow-up.

Breet et al. [20] reported that LTA and 5 other assay methods available for platelet studies were unable to predict which patients were at higher risk of bleeding following stent implantation. In contrast, Tsukahara et al. [27] found that high platelet responsiveness to CLOP or ticlopidine plus ASA, using LTA and ADP as an agonist, is associated with an increased risk of bleeding. Serebruany et al. [28] found that inhibition of platelet aggregation > $50 \%$ using $5 \mu \mathrm{M}$ ADP-induced IPA strongly correlates with minor but not severe bleeding events in a large cohort of patients with coronary artery disease and ischemic stroke treated with chronic low-dose aspirin plus clopidogrel.

Cuiset et al. [29] identified patients post-treatment as hyper-responders when ADP-induced platelet aggregation was below $<40 \%$ (IPA > 60\%). The risk of TIMI major and minor bleeding was significantly higher in these patients.

None of these studies, although they include a large number of patients, deals with BT, the only in vivo test that detects the relationship between vascular endothelium and platelets.

Template BT is an invasive technique displaying low sensitivity to mild or moderate abnormalities of inherited platelet defects. The situation may be different when the effects of drugs are being tested. According to our results, when BT is carried out by experienced personnel, it is a useful technique for evaluating the in vivo effects of antiplatelet agents. Although a number of other platelet function tests have been developed subsequent to BT [30], these tests have shown poor correlation and agreement 
between them, and their clinical usefulness for correctly classifying patients remains undetermined [31,32].

In some circumstances, the cessation of ASA/CLOP treatment (eg, a drug-eluting stent in patients undergoing PCI) is a strong risk factor for thrombosis. Several published studies have shown that patients exhibiting heightened platelet reactivity (ie, low IPA) to antiplatelet agents might be at increased risk of recurrent ischemic events, particularly when they undergo PCI [33-35]. Nevertheless, prediction of bleeding in individual patients remains a challenge.

The important question is whether an antiplatelet agent has the desired effectiveness (ie, thrombosis prevention) with adequate safety (ie, few or no hemorrhagic events). What becomes a problem for the patients is even minor or moderate bleeding, as shown by Rao et al. [36] who pooled the data from 4 multicenter, randomized clinical trials of patients with ACS.

The GUSTO bleeding classification was found to identify patients at risk of short- and long-term death and myocardial infarction. Even though Aronow et al. [37] did not find a significant increase in the overall rate of major or minor thrombolysis in myocardial infarction TIMI score bleeding in patients after PCI when adding CLOP to ASA, major gastrointestinal bleeding increased in the year after PCI. Nuisance bleeding is commonly encountered in patients taking dual antiplatelet therapy, and its incidence and impact are important for compliance. Roy et al. [38] found that $32.4 \%$ reported bleeding events, of which $85.7 \%$ were nuisance, $13.6 \%$ were internal, and $0.7 \%$ were alarming. In the nuisance bleeding group, the rate of CLOP discontinuation was $11.1 \%$.

According to our results in the present study, template BT indicates which patients are prone to bleeding with combined ASA/CLOP therapy, and there is correlation between $\mathrm{BT}$ and IPAmax in response to low concentration of ADP $(2 \mu \mathrm{mol} / \mathrm{L})$ but not at higher concentrations ( 4 or $8 \mu \mathrm{mol} / \mathrm{L})$. This finding is not surprising because BT is indicative of the platelet-endothelial cell interactions and platelet aggregation is indicative of platelet-platelet interactions

The initial step in primary hemostasis is the adhesion of platelets to the subendothelial matrix through specific adhesive glycoproteins. The deposition of platelets on the subendothelium involves the platelet receptor GP Ib/IX/V complex, which interacts with the high molecular weight multimeric plasma protein von Willebrand factor. GPIIb/ IIIa (integrin $\alpha_{I I b} \beta_{3}$ ), which links activated platelets through fibrinogen bridges, is the central platelet receptor in aggregation supporting platelet-platelet interactions. The stimulation of platelets as a result of adhesion leads to a spreading activation of GPIIb/IIIa, enabling the binding of soluble fibrinogen, leading to platelet aggregation and granule secretion [39]. Although interconnected, platelet adhesion and aggregation are different steps in hemostasis, and drugs used therapeutically as antithrombotic agents could affect platelet adhesion, platelet aggregation, or both. Aspirin acts by irreversibly acetylating platelet cyclooxygenase-1, thereby blocking the formation of thromboxane $\mathrm{A}_{2}$. Clopidogrel acts by blocking the $\mathrm{P}_{2} \mathrm{Y}_{12}$ platelet ADP receptor, thereby inhibiting ADP-induced platelet activation and aggregation. The IPA is probably not the exact mechanism of the benefit of ASA and CLOP because of the effect on the many consequences of platelet activation-endothelial relationships [40].

As a result of combining ASA and CLOP, template BT was prolonged ( $\geq 26 \mathrm{~min}$ ) in 55 of 100 patients (55\%); it is pretty clear that this antiplatelet combination affects not only platelet aggregation and thrombin generation [41] but also platelet-endothelial cell interactions, modifying primary hemostasis. This modification could be an important, perhaps the most important, effect for thrombosis prevention. Increasing evidence indicates that platelet adhesion is involved in the earliest development of atherosclerotic lesions [42].

In conclusion, although platelet hyporesponsiveness to CLOP has been associated with major adverse cardiovascular events and stent thrombosis, the risk of increased platelet inhibition is bleeding, which has been strongly linked to mortality [43]. We found that, in patients taking ASA plus CLOP who had a prolonged template BT, bleeding events were frequent. Template BT determined by a trained technician could be useful for following patients treated with dual antiplatelet therapy. Among these patients, those with $\mathrm{BT} \geq 24 \mathrm{~min}$ presented with increased bleeding episodes (nuisance bleeding, epistaxis, hematuria, and proctorrhagia). Moreover, we found correlation between bleeding events and IPAmax in response to feeble concentrations of ADP 2 $\mu \mathrm{mol} / \mathrm{L}$ in LTA, consistent with the hypothesis that lower IPA in response to ADP is associated with increased bleeding risk, but definitive studies are necessary to determine the cutoff point of reactivity to ADP associated with bleeding risk. The present results may have greater relevance with the emergence of more potent antiplatelet drugs [44].

The main limitation of our results is the sample size but the statistical differences in BT between patients with no bleeding and patients with bleeding risk support our findings; a larger study is indicated.

\footnotetext{
Author details

${ }^{1}$ Centro de Trombosis de Buenos Aires, Buenos Aires, Argentina. ${ }^{2}$ Department of Pharmacology, School of Medicine, University of Buenos Aires, Buenos Aires, Argentina. ${ }^{3}$ Favaloro University, Buenos Aires, Argentina.
}

\section{Authors' contributions}

RA designed the study and coordination, drafted the manuscript and discussed the results. AJR carried out the lab assays and discussed the 
results. DCG performed the statistical analysis and discussed the results and participated in its design. All authors read and approved the final manuscript.

\section{Competing interests}

The authors declare that they have no competing interests.

Received: 19 December 2011 Accepted: 11 January 2012

Published: 11 January 2012

\section{References}

1. Yusuf S, Zhao F, Mehta SR, Chrolavicius S, Tognoni G, Fox KK: Effects of clopidogrel in addition to aspirin in patients with acute coronary syndromes without ST-segment elevation. N Engl J Med 2001, 345:494-502.

2. Santa-Cruz RA, Steinhubl SR: Clopidogrel: how good is it and how does it work? Curr Cardiol Rep 2004, 6:264-268.

3. Altman R, Luciardi HL, Muntaner J, Herrera RN: The antithrombotic profile of aspirin. Aspirin resistance, or simply failure? Thromb J 2004, 2:1.

4. Bliden KP, DiChiara J, Tantry US, Bassi AK, Chaganti SK, Gurbel PA: Increased risk in patients with high platelet aggregation receiving chronic clopidogrel therapy undergoing percutaneous coronary intervention: is the current antiplatelet therapy adequate? J Am Coll Cardiol 2007, 49:657-666.

5. Parodi G, Marcucci R, Valenti R, Gori AM, Migliorini A, Giusti B, Buonamici P, Gensini GF, Abbate R, Antoniucci D: High residual platelet reactivity after clopidogrel loading and long-term cardiovascular events among patients with acute coronary syndromes undergoing PCI. JAMA 2011, 306:1215-1223.

6. Gum PA, Kottke-Marchant K, Welsh PA, White J, Topol EJ: A prospective, blinded determination of the natural history of aspirin resistance among stable patients with cardiovascular disease. J Am Coll Cardiol 2003, 41:961-965.

7. Sibbing D, Schulz S, Braun S, Morath T, Stegherr J, Mehilli J, Schömig A, von Beckerath N, Kastrati A: Antiplatelet effects of clopidogrel and bleeding in patients undergoing coronary stent placement. J Thromb Haemost 2010, 8:250-256.

8. Shehab N, Sperling LS, Kegler SR, Budnitz DS: National estimates of emergency department visits for hemorrhage-related adverse events from clopidogrel plus aspirin and from warfarin. Arch Intern Med 2010, 170:1926-1933.

9. Ben-Dor I, Torguson R, Scheinowitz M, Li Y, Delhaye C, Wakabayashi K, Maluenda G, Syed Al, Collins SD, Gonzalez MA, Gaglia MA Jr, Xue Z, Kaneshige K, Satler LF, Suddath WO, Kent KM, Pichard AD, Waksman R: Incidence, correlates, and clinical impact of nuisance bleeding after antiplatelet therapy for patients with drug-eluting stents. Am Heart J 2010, 159:871-875.

10. Tantry US, Kereiakes DJ, Gurbel PA: Clopidogrel and proton pump inhibitors: influence of pharmacological interactions on clinical outcomes and mechanistic explanations. JACC Cardiovasc Interv 2011, 4:365-380.

11. Mehta A, Mehta D, Loganathan J, Paladugu N, Bhalodkar NC: Clopidogrel with proton pump inhibitors: safe or not? Clin Cardiol 2011, 34:528-531.

12. Laine $L$, Hennekens $C$ : Proton pump inhibitor and clopidogrel interaction: fact or fiction? Am J Gastroenterol 2010, 105:34-41.

13. Simon T, Steg PG, Gilard M, Blanchard D, Bonello L, Hanssen M, Lardoux H, Coste $P$, Lefèvre $T$, Drouet $E$, Mulak $G$, Bataille $V$, Ferrières J, Verstuyft $C$, Danchin N: Clinical events as a function of proton pump inhibitor use, clopidogrel use, and cytochrome P450 2C19 genotype in a large nationwide cohort of acute myocardial infarction: results from the French Registry of Acute ST-Elevation and Non-ST-Elevation Myocardial Infarction (FAST-MI) registry. Circulation 2011, 123:474-482.

14. Zafar MU, Ibáñez B, Choi BG, Vorchheimer DA, Piñero A, Jin X, Sharma RK, Badimon JJ: A new oral antiplatelet agent with potent antithrombotic properties: Comparison of DZ-697b with clopidogrel in a randomised phase-I study. Thromb Haemost 2010, 103:205-212.

15. Sugidachi A, Asai $F$, Ogawa $T$, Inoue $T$, Koike $H$ : The in vivo pharmacological profile of CS-747, a novel antiplatelet agent with platelet ADP receptor antagonist properties. Br J Pharmacol 2000, 129:1439-1436

16. Matsushima N, Jakubowski JA, Asai F, Naganuma H, Brandt JT, Hirota T, Freestone S, Winters KJ: Platelet inhibitory activity and pharmacokinetics of prasugrel (CS-747) a novel thienopyridine P2Y12 inhibitor: a multipledose study in healthy humans. Platelets 2006, 17:218-226.

17. Asai F, Jakubowski JA, Naganuma H, Brandt JT, Matsushima N, Hirota T, Freestone S, Winters KJ: Platelet inhibitory activity and pharmacokinetics of prasugrel (CS-747) a novel thienopyridine P2Y12 inhibitor: a single ascending dose study in healthy humans. Platelets 2006, 17:209-217.

18. Jakubowski JA, Matsushima N, Asai F, Naganuma H, Brandt JT, Hirota T, Freestone S, Winters KJ: A multiple dose study of prasugrel (CS-747), a novel thienopyridine P2Y(12) inhibitor, compared with clopidogrel in healthy humans. Br J Clin Pharmacol 2007, 63:421-430.

19. Wilhite DB, Comerota AJ, Schmieder FA, Throm RC, Gaughan JP, Rao AK: Managing PAD with multiple platelet inhibitors: the effect of combination therapy on bleeding time. J Vasc Surg 2003, 38:710-713.

20. Breet NJ, van Werkum JW, Bouman HJ, Kelder JC, Ruven HJ, Bal ET, Deneer VH, Harmsze AM, van der Heyden JA, Rensing BJ, Suttorp MJ, Hackeng CM, ten Berg JM: Comparison of platelet function tests in predicting clinical outcome in patients undergoing coronary stent implantation. JAMA 2010, 303:754-762.

21. Cattaneo M: Aspirin and clopidogrel efficacy, safety, and the issue of drug resistance. Arterioscler Thromb Vasc Biol 2004, 24:1980-1987.

22. Gurbel SP, Bliden KP, Butler K, Tantry US, Gesheff T, Wei C, Teng R, Antonino MJ, Patil SB, Karunakaran A, Kereiakes DJ, Parris C, Purdy D, Wilson V, Ledley GS, Storey RF: Randomized double-blind assessment of the ONSET and OFFSET of the antiplatelet effects of ticagrelor versus clopidogrel in patients with stable coronary artery disease. The ONSET/ OFFSET Study. Circulation 2009, 120:2577-2585.

23. Antonino MJ, Mahla E, Bliden KP, Tantry US, Gurbel PA: Effect of long-term clopidogrel treatment on platelet function and inflammation in patients undergoing coronary arterial stenting. Am J Cardiol 2009, 103:1546-1550.

24. Gremmel T, Steiner S, Seldinger D, Koppensteiner R, Panzer S, Kopp CW: Comparison of methods to evaluates clopidogrel-mediated platelet inhibition after percutaneous intervention with stent implantation. Thromb Haemost 2009, 101:333-339.

25. Paniccia R, Antonucci E, Gori AM, Marcucci R, Giglioli C, Antoniucci D, Gensini GF, Abbate R, Prisco D: Different methodologies for evaluating the effect of clopidogrel on platelet function in high-risk coronary artery disease patients. J Thromb Haemost 2007, 5:1839-1847.

26. Bonello L, Tantry US, Marcucci R, Blindt R, Angiolillo DJ, Becker R, Bhatt DL, Cattaneo M, Collet JP, Cuisset T, Gachet C, Montalescot G, Jennings LK, Kereiakes D, Sibbing D, Trenk D, Van Werkum JW, Paganelli F, Price MJ, Waksman R, Gurbel PA, Working Group on High On-Treatment Platelet Reactivity: Consensus and future directions on the definition of high ontreatment platelet reactivity to adenosine diphosphate. J Am Coll Cardiol 2010, 56:919-933.

27. Tsukahara K, Kimura K, Morita S, Ebina T, Kosuge M, Hibi K, Okuda J, Iwahashi N, Maejima N, Nakachi T, Ohtsuka F, Hashiba K, Tahara Y, Sugano T, Umemura S: Impact of high-responsiveness to dual antiplatelet therapy on bleeding complications in patients receiving drug-eluting stents. Circ J 2010, 74:679-685.

28. Serebruany V, Rao SV, Silva MA, Donovan JL, Kannan AO, Makarov L, Goto S, Atar D: Correlation of inhibition of platelet aggregation after clopidogrel with post discharge bleeding events: assessment by different bleeding classifications. Eur Heart J 2010, 31:227-235.

29. Cuisset T, Cayla G, Frere C, Quilici J, Poyet R, Gaborit B, Bali L, Morange PE, Alessi MC, Bonnet JL: Predictive value of post-treatment platelet reactivity for occurrence of post-discharge bleeding after non-ST elevation acute coronary syndrome. Shifting from antiplatelet resistance to bleeding risk assessment? Eurolntervention 2009, 5:325-329.

30. Harrison P, Keeling D: Clinical tests of platelet function. In Platelets.. 2 edition. Edited by: Michelson AD. San Diego, CA: Elsevier/Academic Press; 2006:445-474.

31. Lordkipanidzé M, Pharand C, Schampaert E, Turgeon J, Palisaitis DA, Diodati JG: A comparison of six major platelet function tests to determine the prevalence of aspirin resistance in patients with stable coronary artery disease. Eur Heart J 2007, 28:1702-1708.

32. Harrison P, Frelinger AL, Furman MI, Michelson AD: Measuring antiplatelet drug effects in the laboratory. Thromb Res 2007, 120:323-336.

33. Bliden KP, DiChiara J, Tantry US, Bassi AK, Chaganti SK, Gurbel PA: Increased risk in patients with high platelet aggregation receiving chronic clopidogrel therapy undergoing percutaneous coronary intervention: is 
the current antiplatelet therapy adequate? J Am Coll Cardiol 2007, 49:657-666.

34. Matetzky S, Shenkman B, Guetta V, Shechter M, Beinart R, Goldenberg I, Novikov I, Pres H, Savion N, Varon D, Hod H: Clopidogrel resistance is associated with increased risk of recurrent atherothrombotic events in patients with acute myocardial infarction. Circulation 2004, 109:3171-3175.

35. Gum PA, Kottke-Marchant K, Welsh PA, White J, Topol EJ: A prospective, blinded determination of the natural history of aspirin resistance among stable patients with cardiovascular disease. J Am Coll Cardiol 2003, 41:961-965.

36. Rao SV, O'Grady K, Pieper KS, Granger CB, Newby LK, Van de Werf F, Mahaffey KW, Califf RM, Harrington RA: Impact of bleeding severity on clinical outcomes among patients with acute coronary syndromes. Am J Cardiol 2005, 96:1200-1206.

37. Aronow HD, Steinhubl SR, Brennan DM, Berger PB, Topol EJ, CREDO Investigators: Bleeding risk associated with 1 year of dual antiplatelet therapy after percutaneous coronary intervention: Insights from the Clopidogrel for the Reduction of Events During Observation (CREDO) trial. Am Heart J 2009, 157:369-374.

38. Roy P, Bonello L, Torguson $\mathrm{R}$, de Labriolle A, Lemesle $\mathrm{G}$, Slottow $T L$, Steinberg DH, Kaneshige K, Xue Z, Satler LF, Kent KM, Suddath WO, Pichard AD, Lindsay J, Waksman R: Impact of "nuisance" bleeding on clopidogrel compliance in patients undergoing intracoronary drugeluting stent implantation. Am J Cardiol 2008, 102:1614-1617.

39. Altman R, Scazziota A, Herrera ML: Principles of antiplatelet therapy. In Interventional Cardiovascular Pharmacology. Edited by: Kipshidze N, Fareed J, Moses JW, Serruys PW. UK: Informa Healthcare; 2007:31-40.

40. Santa-Cruz RA, Steinhubl SR: Clopidogrel: how good is it and how does it work? Curr Cardiol Rep 2004, 6:264-268.

41. Altman R, Scazziota A, De Lourdes Herrera M, Gonzalez C: Recombinant factor VIla reverses the inhibitory effect of aspirin or aspirin plus clopidogrel on in vitro thrombin generation. J Thromb Haemost 2006, 4:2022-2027.

42. Maree AO, Fitzgerald DJ: Variable platelet response to aspirin and clopidogrel in atherothrombotic disease. Circulation 2007, 115:2196-2207.

43. Stone GW: Ischaemia versus bleeding: the art of clinical decision-making Lancet 2009, 373:695-696.

44. Wiviott SD, Braunwald E, McCabe CH, Montalescot G, Ruzyllo W, Gottlieb S, Neumann FJ, Ardissino D, De Servi S, Murphy SA, Riesmeyer J, Weerakkody G, Gibson CM, Antman EM, TRITON-TIMI 38 Investigators: Prasugrel versus clopidogrel in patients with acute coronary syndromes. N Engl J Med 2007, 357:2001-2015.

doi:10.1186/1477-9560-10-3

Cite this article as: Altman et al:: Bleeding tendency in dual antiplatelet therapy with aspirin/clopidogrel: rescue of the template bleeding time in a single-center prospective study. Thrombosis Journal 2012 10:3.

\section{Submit your next manuscript to BioMed Central and take full advantage of:}

- Convenient online submission

- Thorough peer review

- No space constraints or color figure charges

- Immediate publication on acceptance

- Inclusion in PubMed, CAS, Scopus and Google Scholar

- Research which is freely available for redistribution

Submit your manuscript at www.biomedcentral.com/submit
Biomed Central 